\title{
Prevalence of otitis media and risk factors for sensorineural hearing loss among infants attending routine well-baby clinics in urban and rural/remote Samoa: a study protocol
}

\author{
Annette Kaspar ${ }^{1}$ (), Sione Pifeleti ${ }^{2}$, Carlie Driscoll ${ }^{3}$ \\ ${ }^{1}$ ENT Department, Tupua Tamasese Meaole Hospital, Ministry of Health, Apia, Samoa; Hearing Research Unit for Children, School of Health and \\ Rehabilitation Sciences, University of Queensland, Brisbane, Australia, 2 ENT Department, Tupua Tamasese Meaole Hospital, Ministry of Health, Apia, \\ Samoa, ${ }^{3}$ Hearing Research Unit for Children, School of Health and Rehabilitation Sciences, University of Queensland, Brisbane, Australia \\ Keywords: otitis media, hearing, child health, health promotion, pacific islands \\ https://doi.org/10.29392/001c.21427
}

Journal of Global Health Reports

Vol. 5, 2021

\begin{abstract}
Background
The World Health Organization recommends newborn and infant hearing screening programs for all member states to enable early detection and intervention for children with hearing loss. Ear and hearing services are limited in the Pacific Islands, a region with one of the highest global rates of ear disease and hearing loss. Given that a significant proportion of childhood hearing loss is preventable through public health measures, collaboration with existing primary and public health platforms should reduce the prevalence of avoidable ear and hearing disorders among infants and young children. Previous work has investigated an infant ear and hearing program for child welfare clinics in an urban Pacific Island setting. The present study will build on this previous work by investigating the possibility of an Infant Ear and Hearing Program in a different Pacific Island country, and performing comparisons between urban and rural/remote populations.
\end{abstract}

\section{Methods and analysis}

We propose a cross-sectional study of infants attending well-baby clinics in urban (Apia), rural (Upolu), and remote (Savai'i) Samoa. All participating infants will undergo an ear examination of both ears, and as assessment of risk factors for permanent hearing loss.

\section{Ethics and and conclusions}

We publish these protocols to facilitate similar studies in other low- and middle-Income countries, and especially among our Pacific Island neighbours. We anticipate that $25 \%$ of infants will present with ear pathology in at least one ear, and that $25 \%$ of infants will present with at least one risk factor for permanent hearing loss. This study was approved by the Government of Samoa Ministry of Health Ethical Research Committee and the University of Queensland Medical Ethics Research Committee.

The World Health Organization (WHO) recommends that newborn and infant hearing screening should be the goal of all member states. ${ }^{1}$ Early identification and intervention for infants with hearing loss should reduce the well-known adverse effects of hearing loss on childhood development and social well-being. The Sustainable Development Goal (SDG) Project offers an opportunity for the implementation of infant ear and hearing programs in the Pacific Islands.

The Pacific Island region has among the highest rates of ear disease and hearing loss in the world. ${ }^{2,3}$ Otitis media begins early in life, and may progress to chronic and possibly life-threatening complications if poorly managed. ${ }^{4}$ Previous work from the Solomon Islands found that parents are very supportive of community ear and hearing services for children. ${ }^{5}$ A pilot study at child welfare clinics in the Solomon Islands further found that a quarter of infants pre- sented with ear pathology in at least one ear, and a quarter of infants also presented with at least one risk-factor for sensorineural (permanent) hearing loss. ${ }^{6}$ The study was conducted in the capital city Honiara, and it is likely that results may differ in rural/remote regions. There are no other research studies of this kind from the Pacific Islands.

Samoa is a Polynesian nation of the Pacific Islands (Figure 1). The Ear, Nose \& Throat (ENT) Clinic of the Tupua Tamasese Meaole (TTM) Hospital in Samoa was established in 2017 under the leadership of the General/ENT surgeon (author SP). It is the only ENT Clinic in the country. Public health, development and research audiologist (author AK) joined the Samoan ENT clinic team in 2019, and implementation of routine community outreach visits became a priority for the clinic. Improving the rate of early detection and management of ear disease, should in turn reduce the rate 
of preventable hearing loss among children in Samoa. Wellbaby clinics are an ideal platform for early parental education on basic ear health care and signs/symptoms for attending health services. The role of caregivers in reducing the prevalence of ear disease and hearing loss among children cannot be underestimated.

The aim of the proposed study is to describe the prevalence of otitis media and risk factors for sensorineural hearing loss among infants attending routine well-baby clinics in urban and rural/remote Samoa. The results of the study should provide evidence for the formal implementation of infant ear and hearing screening at well-baby clinics (i.e. inclusion of risk-factor questionnaire in the child health record book). This would be the first step towards newborn and infant hearing screening as described by the WHO. The study will expand on the previous work from the Solomon Islands by assessing infants from both urban and rural/remote settings. It will enable comparison between two different Pacific Islands, and may provide insights into ear/ hearing health differences between Melanesian and Polynesian nations.

Our aim in publishing this study protocol is to facilitate similar studies of this kind, especially among our Pacific Island neighbours. Even where audiologists are unavailable, the implementation of routine ear examinations and the risk-factor questionnaire for permanent hearing loss by an appropriate health professional (i.e. well-baby clinic nurses) should positively contribute to reducing ear disease and associated hearing loss among infants and children in the Pacific Islands.

\section{METHODS}

\section{PLANNING AND PREPARATION}

\section{ETHICS APPROVAL}

This study was approved by the Government of Samoa Ministry of Health Ethical Research Committee and the University of Queensland Medical Ethics Research Committee (Approval No. 2020000255).

\section{AIM}

The aims of the proposed study are to describe the prevalence of ear disease and risk-factors for sensorineural (permanent) hearing loss among Samoan infants living in Apia (urban), Upolu (rural), and Savai'i (remote). The results will provide baseline data for comparison with subsequent surveys, and enable monitoring and evaluation of any changes in the rate of ear disease and hearing loss among infants and young children.

We hypothesise the following:

- The prevalence of ear disease will be significantly higher among infants living in rural/remote Samoa than in the urban capital city Apia,

- The prevalence of risk-factors for hearing loss will be significantly higher among infants living in rural/remote Samoa than in the urban capital city Apia,

- No significant difference in prevalence of ear disease will be found between urban infants living in Samoa

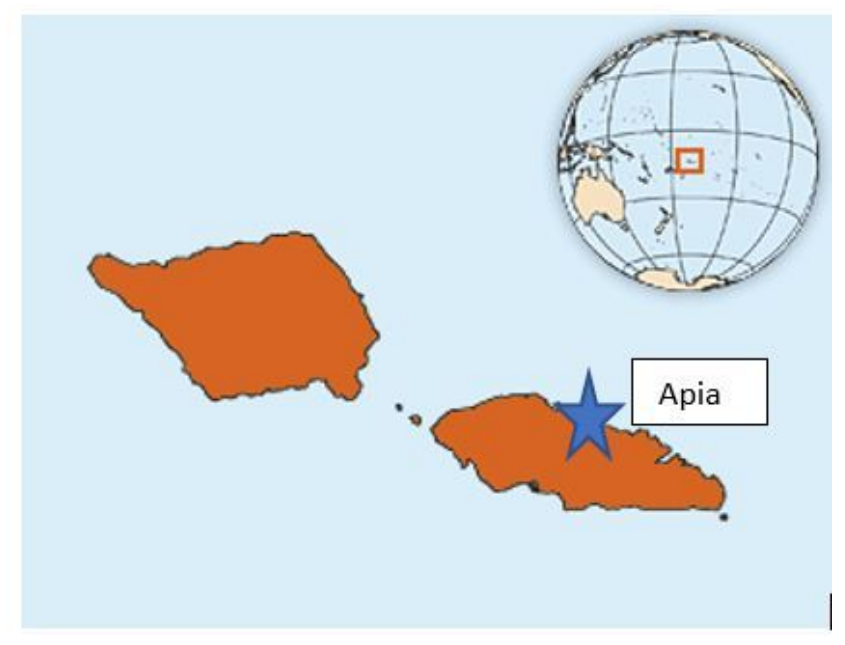

Figure 1. Map of Samoa.

and the Solomon Islands,

- No significant difference in prevalence of risk-factors for hearing loss will be found between urban infants living in Samoa and the Solomon Islands,

\section{PERSONNEL}

The study will be led by the research audiologist (AK) and the head of ENT clinic (SP). The ENT specialist will perform the ear examinations. The ENT

clinic nurses will administer the Joint Committee on Infant Hearing (JCIH)

risk-factor questionnaire, as well as perform any interventions as required

(i.e., earwax removal). Data analysis will be performed in collaboration with the Hearing Research Unit for Children at the University of Queensland (Australia) and includes consultation with a biostatistician (CD).

\section{DESIGN}

The study will use a cross-sectional survey and convenience sampling design. This method was used in previous studies of this kind, and is a cost-effective method appropriate for this population.

\section{SETTING}

The study will be set at participating well-baby clinics in Apia, Upolu, and Savai'i.

\section{PARTICIPANTS}

The study population will consist of a representative sample of infants aged 0-12 months attending routine well-baby clinics in Apia, Upolu, and Savai'i.

The minimum sample size will be 600 infants. There will be a minimum of 200 infants from each setting type, i.e. minimum 200 infants from Apia, minimum of 200 infants from Upolu, and a minimum of 200 infants from Savai'i. 


\section{ASSESSMENT}

Routine ENT and Audiology Clinical assessment. The ENT Specialist will perform an ear examination for each ear, and, if required, ENT nurses will perform interventions (i.e., wax removal). The ENT nurses will administer the Joint Committee on Infant Hearing Risk-Factor Questionnaire which has been updated for our Samoan context. ${ }^{7}$

The results for each infant will be communicated to their parents/caregiver at the time of the assessment, and recommendations/reviews will follow routine ENT/audiology clinic procedure.

\section{EQUIPMENT AND CONSUMABLES}

Routine clinical equipment will be used in the study. There is no consumable equipment as otoscopy probe tips are sterilized daily and re-used.

- Otoscope/Vorotek (for ear examinations)

- Suction machine (for any nurse interventions)

The following will be contained within a simple plastic folder for utilization by the research team:

- Information sheet for participants (English) - Prevalence of otitis media and risk-factors for sensorineural hearing loss among infants attending routine well-baby clinics in urban and rural/remote Samoa.

- Information sheet for participants (Samoan) - Prevalence of otitis media and risk-factors for sensorineural hearing loss among infants attending routine well-baby clinics in urban and rural/remote Samoa.

- Participant consent form (English) - Prevalence of otitis media and risk-factors for sensorineural hearing loss among infants attending routine well-baby clinics in urban and rural/remote Samoa.

- Participant consent form (Samoan) - Prevalence of otitis media and risk-factors for sensorineural hearing loss among infants attending routine well-baby clinics in urban and rural/remote Samoa.

- Data collection (English) - Prevalence of otitis media and risk-factors for sensorineural hearing loss among infants attending routine well-baby clinics in urban and rural/remote Samoa.

- Staff member business cards with contact details

- Pens

To reduce the cost of consumables, the Samoan version of the consent form and the data collection form will be printed back-to-back on the same sheet of paper for use in the study (English version present for benefit of team leader only). Similarly, a laminated copy of the Samoan version of the information sheet and 5 non-laminated copies only will be in the study folder (information sheets to be kept by individuals only if requested).

\section{QUALITY CONTROL}

The following measures will be implemented to ensure maximum quality control for the study:
- Daily maintenance of all clinical equipment (sterilization, etc.),

- All staff will be informed of the record-keeping requirements of the study to ensure optimal documentation,

- Regular review with the team leader during the study period to enable any clarification of issues if/as they arise,

- Signature of staff member(s) on the data collection form, and

- Team leader provides update and feedback on the study at staff meetings, and promotes team input for improvement of the clinical service.

\section{CONDUCTING THE STUDY}

The recommended work flow on the day(s) of data collection is summarized in Figure 2.

\section{RECRUITMENT OF PARTICIPANTS}

On the day(s) of data collection, an announcement will be made by one of the research team to the mothers/caregivers attending the well-baby clinic with their infant. The announcement will be made at the start of the day, and then at regular intervals throughout the day. The announcement will introduce the members of the research team, and then describe the aims of the project and the participant requirements. Attending mothers/caregivers will then be invited to allow their infant to participate in the study.

Mothers/caregivers willing for their infant to participate in the study will be shown to a private area that has been allocated for the project. They will be given more detailed information on the study (i.e. information sheet), and asked to sign the consent form (infant name/infant date of birth/ mother - caregiver name/signature/date) if they are still willing for their infant to participate.

\section{DATA COLLECTION}

The ENT/audiology clinic staff members performing the data collection will complete the data collection form purposefully designed for this study.

DEMOGRAPHIC INFORMATION

The following demographic information will be recorded:

- Infant Name

- Date of Birth

- Age (in months)

- Gender

- Well-Baby Clinic Location

ENT CONSULTATION

All infants will undergo ear examination for both ears. An overall diagnosis for each ear is made as per routine ENT clinic protocols:

- No abnormalities detected: NAD

- Acute Otitis Media: AOM

- Acute Otitis Media with Perforation: AOMwiP

- Chronic Suppurative Otitis Media: CSOM 


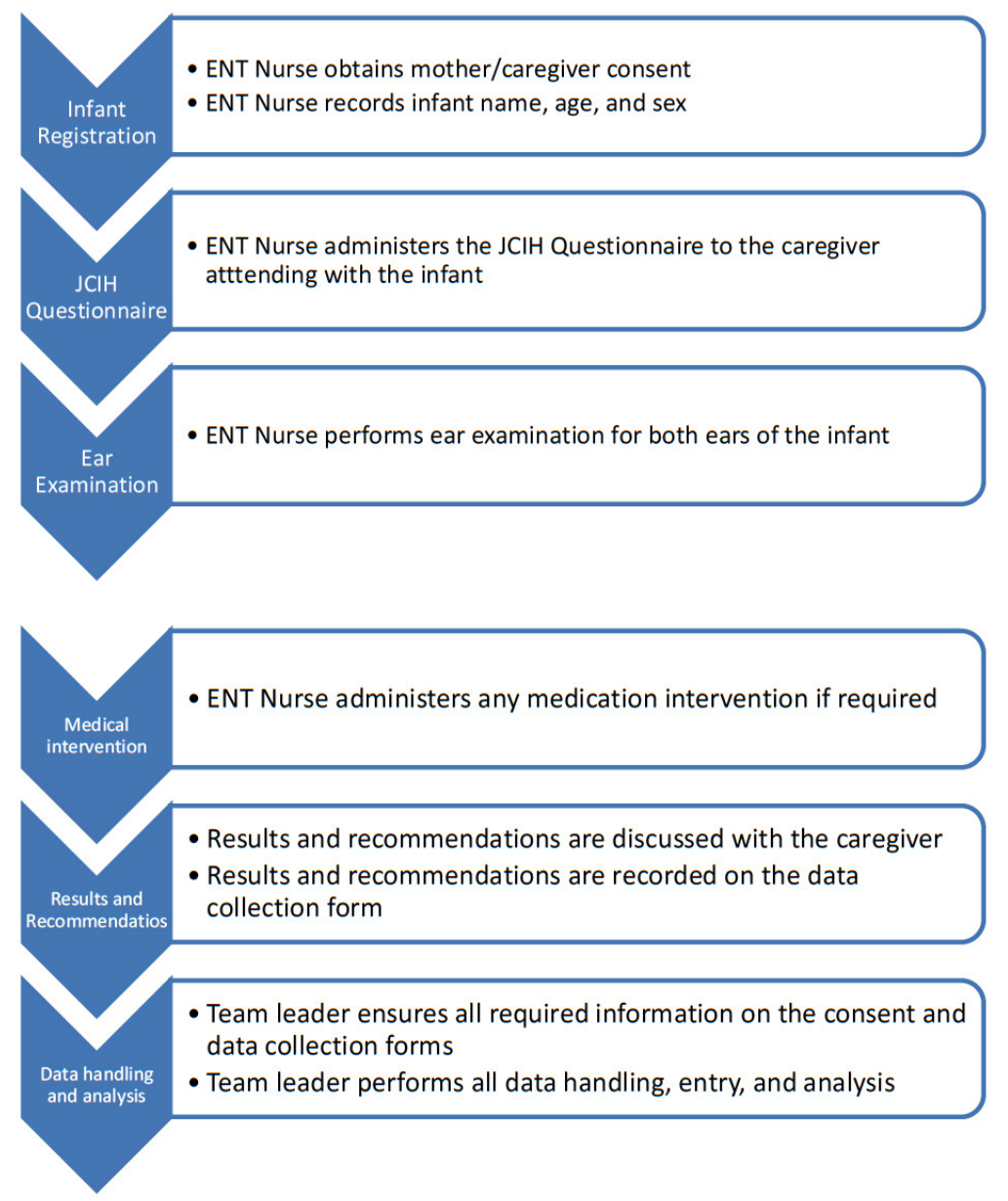

Figure 2. Prevalence of otitis media and risk-factors for sensorineural hearing loss among infants attending well-baby clinics in Samoa - work flow chart.

ENT - Ear Nose and Throat.

- Dry Tympanic Membrane Perforation: Dry TM Perf

- Otitis Media with Effusion: OME

- Eustachian Tube Dysfunction: ETD

- Impacted Cerumen

- Foreign Body

- Fungal Otitis Externa

- Could not assess

Should wax removal, foreign body removal, or aural toilet be required, the ENT Consultant will direct the ENT nurses to perform this task.

ENT medical or surgical intervention will be recommended as appropriate.

JCIH RISK-FACTOR QUESTIONNAIRE FOR HEARING LOSS

The JCIH risk-factor questionnaire for hearing loss will be administered (Table 1). The ENT nurses will ask all items on the questionnaire, commencing at Question 1 and ending at Question 14. The mother/caregiver will be asked to respond with "Yes", "No", or "Unsure". The following information will be obtained from the Child Health Record: cranio-facial anomalies, syndromes associated with hearing loss, prematurity/low birthweight, birth asphyxia, and/or Apgar score 0-6 at 5 minutes, mechanical ventilation last- ing 5 days or more, ototoxic medication, bacterial meningitis, hyperbilirubinemia, and undernutrition. All other responses will rely on parental report.

\section{RESULTS AND RECOMMENDATIONS}

The results and recommendations will be communicated to the mother/caregiver at the time of the assessment, and recorded on the data collection form.

- For infants with no risk-factors for sensorineural (permanent) hearing loss and no abnormalities on ear examination, routine well-baby clinic review is recommended as per well-baby clinic protocols.

- For infants with one or more risk-factors for sensorineural (permanent) hearing loss, monitoring of speech and language milestones is recommended as described in the Baby Health Book (Table 2). Referral to SENESE may be warranted if there are existing concerns regarding speech/language development.

- For infants diagnosed with ear pathology, review and recommendations follow routine ENT Clinic protocols. 
Table 1. Modified Joint Committee on Infant Hearing (JCIH) risk factor questionnaire

\begin{tabular}{|c|c|c|c|c|}
\hline \# & Risk factor classification & Yes & No & Unsure \\
\hline & Perinatal & & & \\
\hline 1 & Family history of early, progressive, or delayed onset permanent childhood hearing loss & & & \\
\hline 2 & Neonatal intensive care of more than 5 days & & & \\
\hline 3 & Hyperbilirubinemia & & & \\
\hline 4 & Aminoglycoside administration for more than 5 days & & & \\
\hline 5 & Asphyxia or Hypoxic Ischemic Encephalopathy & & & \\
\hline 6 & Extracorporeal membrane oxygenation (ECMO) & & & \\
\hline 7 & In utero infections, such as herpes, rubella, syphilis, and toxoplasmosis & & & \\
\hline 8 & $\begin{array}{l}\text { Certain birth conditions or findings: } \\
\text { - Craniofacial malformations including microtia/atresia, ear dysplasia, oral facial clefting, } \\
\text { white forelock, and microphthalmia } \\
\text { - Congenital microcephaly, congenital or acquired hydrocephalus } \\
\text { - Temporal bone abnormalities }\end{array}$ & & & \\
\hline \multirow[t]{2}{*}{9} & Syndrome: & & & \\
\hline & Perinatal or Postnatal & & & \\
\hline 10 & Infections associated with sensorineural hearing loss, including meningitis or encephalitis & & & \\
\hline 11 & $\begin{array}{l}\text { Events associated with hearing loss: } \\
\text { - Significant head trauma especially basal skull/temporal bone fractures }\end{array}$ & & & \\
\hline \multirow[t]{2}{*}{12} & $\begin{array}{l}\text { Caregiver concern regarding hearing, speech, language, development delay and/or } \\
\text { development regression }\end{array}$ & & & \\
\hline & Emerging factors from LMICs & & & \\
\hline 13 & Maternal hypertensive disorders in pregnancy & & & \\
\hline 14 & Non-elective caesarean delivery & & & \\
\hline 15 & Unskilled attendant at delivery & & & \\
\hline \multirow[t]{2}{*}{16} & Undernutrition & & & \\
\hline & Possible risk-factor for the Pacific Islands & & & \\
\hline 17 & Gestational diabetes & & & \\
\hline
\end{tabular}

LMICs - low- and middle-income countries, Source: ${ }^{6,7}$

\section{DATA HANDLING AND ANALYSIS}

All data handling and analysis will be done by the team leader.

- All completed consent and data collection forms will be given to the team leader by the other staff member(s),

- The team leader will review all forms to ensure all items are completed. Where information is missing, the team leader will consult the relevant staff member and, if appropriate, contact the participant,

- The team leader will assign a code-identifier to each participant. This will be entered on the top right-hand corner of the Consent forms, and

- The team leader will enter all data into "Data Entry Spreadsheet Prevalence of otitis media and risk-factors for sensorineural hearing loss among infants attending routine well-baby clinics in urban and rural/ remote Samoa". The coding strategy is given in Table 3.

The team leader will analyse the data to provide the fol- lowing information:

DEMOGRAPHIC INFORMATION

A descriptive analysis will be performed for the total number of infants seen by the TTM ENT/audiology clinic from January to December 2021. The analysis will include gender and age range (mean and standard deviation). Results will be presented in tabulated form using a cross-analysis (i.e., age subgroup $\mathrm{x}$ gender $\mathrm{x}$ well-baby clinic location).

ANALYSIS OF VARIABLES

The overall prevalence of ear disease and risk-factors for hearing loss among this sample of infants will be presented as a percentage (\%): ie. \% of infants presented with no ear disease and no risk-factors for permanent hearing loss, \% of infants presented with ear disease in at least one ear, \% of infants presented with at least one risk-factor for permanent hearing loss, and \% of infants presented with both ear disease in at least one ear and at least one risk-factor for permanent hearing loss.

A descriptive analysis will be provided for ENT consul- 
Table 2. Hearing screening questionnaire for babies

\begin{tabular}{|c|c|c|c|}
\hline Age of baby & Question & Yes & No \\
\hline \multirow{2}{*}{$\begin{array}{l}\text { A few weeks } \\
\text { old }\end{array}$} & Does your baby open his/her eyes or blink when there is a noise? & & \\
\hline & Does your baby appear to be listening to you when you talk or sing? & & \\
\hline \multirow[t]{2}{*}{$\begin{array}{l}\text { About } 6 \\
\text { months }\end{array}$} & $\begin{array}{l}\text { Does your baby try to see where the noise is coming from by turning his/her eyes or head } \\
\text { towards the sound? }\end{array}$ & & \\
\hline & Does your baby enjoy you talking to him/her? & & \\
\hline \multirow{2}{*}{$\begin{array}{l}\text { About } 9 \\
\text { months }\end{array}$} & Does your baby appear to respond to even very soft sounds? & & \\
\hline & Does your baby enjoy babbling and making other sounds? & & \\
\hline \multirow[t]{2}{*}{ About 1 year } & $\begin{array}{l}\text { Does your baby respond when you say his/her name and the name of the things they play } \\
\text { with? }\end{array}$ & & \\
\hline & Is your baby starting to say baby words? & & \\
\hline \multirow{2}{*}{$\begin{array}{l}\text { About } 18 \\
\text { months }\end{array}$} & Does your baby pick up or point to things around the house when you ask them to do this? & & \\
\hline & Is your baby starting to use simple words? & & \\
\hline \multirow[t]{2}{*}{2 years old } & $\begin{array}{l}\text { Do you think your baby can hear normally even when you speak to him/her in a very soft } \\
\text { voice? }\end{array}$ & & \\
\hline & Is your baby putting words together and trying to talk to you? & & \\
\hline
\end{tabular}

Source: WHO Primary Ear and Hearing Care Intermediate Level Training Package.

tant diagnosis, nurse intervention, and outcomes of the ENT/audiology assessment. For each item of the JCIH riskfactor questionnaire, the number of "Yes", "No", or "Unsure" responses will be tallied.

Chi-squared linear-by-linear association tests will be performed to investigate for any significant associations between the ENT/audiology assessment results, and gender, age, and clinic location group variables. Comparison will also be made between results from Samoa and the Solomon Islands. Any significant findings will be highlighted.

\section{DISCUSSION}

The results of this study will be prepared as a research paper for submission to a peer-reviewed journal. Similar studies have been published in the International Journal of Pediatric Otorhinolaryngology and the International Journal of Audiology. The published paper will be also be delivered to the Government of Samoa Ministry of Health, including an action plan for ENT/audiology services, health education, and health promotion activities based on the results.

The ENT/audiology clinic will collaborate with Health Promotion Officers to prepare a short media release about the study and the results. This will be done in consultation with the Government of Samoa Ministry of Health to ensure information is appropriate and receives maximum population coverage. The aim of the media release is (i) to create awareness of the prevalence of ear disease and risk-factors for permanent hearing loss among infants and young children, (ii) to increase community awareness of avoidable ear disease and hearing loss, and (iii) to encourage timely attendance at health services for treatment of ear disease and suspicions of childhood hearing loss.

We include the English versions of the Participant Information Sheet and Participant Consent Form as additional files with this publication to further facilitate similar stud- ies of this kind, especially among our Pacific Island neighbors.

\section{ACKNOWLEDGMENTS}

Thank you to the Editor-in-Chief of the International Journal of Pediatric Otorhinolaryngology (IJPO) for granting permission to publish amended parts of the manual previously published in IJPO for the original study in the Solomon Islands by author AK. Publication of the present study protocol should facilitate similar studies in other LMICs, especially among our Pacific Island neighbours.

\section{ETHICS APPROVAL AND CONSENT TO PARTICIPATE}

This study was approved by the Government of Samoa Ministry of Health Ethical Research Committee and the University of Queensland Medical Ethics Research Committee (Approval No. 2020000255). All participants will sign a consent form prior to data collection.

\section{AVAILABILITY OF DATA AND MATERIALS}

All data generated or analyzed during this study will be included in the published article.

\section{FUNDING}

None.

\section{AUTHORSHIP CONTRIBUTIONS}

AK wrote the initial draft manuscript, and all authors provided feedback. AK performed revisions to the manuscript as appropriate, and all authors read and approved the final 
Table 3. Prevalence of otitis media and risk-factors for sensorineural hearing loss among infants attending routine well-baby clinics in urban and rural/remote Samoa: coding strategy

\begin{tabular}{|c|c|c|}
\hline Description & & Code \\
\hline \multirow[t]{3}{*}{ Location } & Apia & 1 \\
\hline & Upolu & 2 \\
\hline & Savai'i & 3 \\
\hline \multirow[t]{2}{*}{ Sex } & Male & 1 \\
\hline & Female & 2 \\
\hline \multirow[t]{2}{*}{ Age category } & $0-6$ months & 1 \\
\hline & 6-12 months & 2 \\
\hline \multirow[t]{3}{*}{ Measles infection } & Yes & 1 \\
\hline & No & 2 \\
\hline & Unsure & 3 \\
\hline \multirow[t]{3}{*}{ JCIH questionnaire response } & Yes & 1 \\
\hline & No & 2 \\
\hline & Unsure & 3 \\
\hline \multirow[t]{9}{*}{ Ear examination } & NAD & 1 \\
\hline & AOM & 2 \\
\hline & AOMwiP & 3 \\
\hline & CSOM & 4 \\
\hline & Dry TM perforation & 5 \\
\hline & OME & 6 \\
\hline & ETD & 7 \\
\hline & Impacted cerumen & 8 \\
\hline & Could not assess & 9 \\
\hline \multirow[t]{4}{*}{ Review } & Routine well-baby clinic review & 1 \\
\hline & ENT review & 2 \\
\hline & Monitor speech and language milestones & 3 \\
\hline & ENT review \& monitoring of speech and language milestones & 4 \\
\hline
\end{tabular}

NAD - No Abnormalities Detected, AOM - Acute Otitis Media, AOMwiP - Acute Otitis Media with Perforation, CSOM - Chronic Suppurative Otitis Media, TM - Tympanic Membrane, OME - Otitis Media with Effusion, ETD - Eustachian Tube Dysfunction, ENT - Ear, Nose and Throat, JCIH - Joint Committee on Infant Hearing

manuscript.

\section{COMPETING INTERESTS}

The authors completed the Unified Competing Interest form at www.icmje.org/coi disclosure.pdf (available upon request from the corresponding author), and declare no conflicts of interest.

\section{CORRESPONDENCE TO:}

\section{Annette Kaspar}

ENT Department, Tupua Tamasese Meaole Hospital Ministry of Health, Apia, Samoa. annette.kaspar@gmail.com

Submitted: December 18, 2020 GMT, Accepted: February 24, 2021 GMT 


\section{REFERENCES}

1. WHO. Newborn and infant hearing screening. Current issues and guiding principles for action. Published 2010. https://www.who.int/blindness/publi cations/Newborn_and_Infant_Hearing_Screening_Rep ort.pdf?ua $=1$

2. Monasta L, Ronfani L, Marchetti F, et al. Burden of disease caused by otitis media: systematic review and global estimates. PLOS ONE. 2012;7(4):e36226. doi:1 0.1371/journal.pone.0036226

3. WHO. WHO Global estimates on prevalence of hearing loss. Published 2018. Accessed January 26, 2019. https://www.who.int/pbd/deafness/estimates/e n/

4. Kaspar A, Kei J, Driscoll C, Swanepoel DW, Goulios H. Overview of a public health approach to pediatric hearing impairment in the Pacific Islands.

International Journal of Pediatric Otorhinolaryngology. 2016;86:43-52. doi:10.1016/i.ijporl.2016.04.018
5. Kaspar A, Newton O, Kei J, Driscoll C, Swanepoel DW, Goulios H. Parental knowledge and attitudes to childhood hearing loss and hearing services in the Solomon Islands. International Journal of Pediatric Otorhinolaryngology. 2017;103:87-92. doi:10.1016/j.ij porl.2017.10.003

6. Kaspar A, Newton O, Kei J, Driscoll C, Swanepoel DW, Goulios H. Prevalence of otitis media and riskfactors for sensorineural hearing loss among infants attending Child Welfare Clinics in the Solomon Islands. International Journal of Pediatric Otorhinolaryngology. 2018;111:21-25. doi:10.1016/j.ij porl.2018.05.021

7. JCIH. Year 2019 Position Statement: Principles and Guidelines for Early Hearing Detection and Intervention Programs. Journal of Early Hearing Detection and Intervention. 2019;4(2):1-44. doi:10.151 $\underline{42 / f p t k-b 748}$ 